\title{
CERTIDÃO DE NASCIMENTO: a redução sociológica em seu contexto de publicação
}

\author{
Edison Bariani*
}

\begin{abstract}
Decorrido mais de meio século desde a publicação de A redução sociológica, de Alberto Guerreiro Ramos, o livro continua sendo um marco das ciências sociais, principalmente da sociologia no Brasil. Entretanto, cabe ainda lançar alguma luz sobre o contexto social e o contexto intelectual no qual a obra foi produzida, bem como sua recepção crítica naquele momento. Também, restam ainda alguns aspectos a serem analisados a partir da perspectiva atual, ou seja, um balanço e revisão da importância desta obra na cultura brasileira, do que já acusa a ação do tempo e do que permanece atual e mesmo do ainda não foi devidamente analisado.

Palavras-chave: Guerreiro Ramos. Redução Sociológica. Periferia. Recepção. Sociologia Brasileira.
\end{abstract}

Em 1958, 57 anos atrás, Guerreiro Ramos, lançava seu último livro como integrante do Instituto Superior de Estudos Brasileiros (ISEB), sua obra até então (talvez até hoje) mais ousada: A redução sociológica.

Naquele ano, o Brasil se tornou campeão mundial de futebol, o C. R. Vasco da Gama conquistou o campeonato no Rio de Janeiro e o Santos F. C., em São Paulo. Foi iniciada a produção em série do Volkswagen Sedan (Fusca) e vivia-se a euforia do Governo Juscelino Kubitschek. No ano anterior, havia começado a construção de Brasília; persistia a influência da Comissão Econômica para a América Latina (CEPAL), depois também Caribe, na interpretação econômica, e o PCB lançava sua Declaração de Março. Jorge Amado publicava Gabriela, Cravo e Canela; Raimundo Faoro, Os donos do poder; Sérgio Buarque de Holanda, a Visão do paraíso; Roger Bastide, O candomblé da Bahia; Costa Pinto, Recôncavo; Celso

* Doutor em Sociologia. Professor da Faculdade Santa Rita (FASAR) de Novo Horizonte-SP, da Faculdade de Itápolis -SP (FACITA), do IMES (Catanduva).

Universidade Estadual Paulista Júlio de Mesquita Filho, Faculdade de Ciências e Letras de Araraquara. Departamento de Sociologia. Rodovia Washington Luiz. Cep: 1490000. Araraquara - São Paulo - Brasil. edsnb@ig.com.br
Furtado, Perspectivas da economia brasileira. No ambiente um tanto conturbado do ISEB, Roland Corbisier publicava Formação e problema da cultura brasileira; Nelson Werneck Sodré, Introdução à revolução brasileira; Álvaro Vieira Pinto traduzia e publicava o livro de Karl Jaspers, Razão e anti-razão em nosso tempo; e Hélio Jaguaribe publicava Condições institucionais do desenvolvimento e O nacionalismo na atualidade brasileira. Esse último livro daria ensejo, naquele mesmo ano, às suas desavenças com Guerreiro Ramos, culminando com a saída de ambos do instituto (Sodré, 1978, 1992).

No mundo, a Guerra Fria estava em plena vigência, os revolucionários cubanos atacavam Havana e estavam próximos da tomada do poder. Nikita Khrushchev tornava-se o premiê da então União Soviética; Charles de Gaulle era chamado a formar um novo governo francês (que promulgou nova constituição e fundou a Quinta República); os nacionalistas iraquianos derrubavam a monarquia do rei Faisal II por meio de uma revolução e subia ao poder Abdul Karim Qassim; Arturo Frondizi era eleito Presidente da Argentina; conflitos entre negros 
e brancos aconteciam em Londres; o Papa Pio XII falecia e era substituído por João XXIII; as colônias francesas e inglesas na África começavam a se rebelar e a pleitear autonomia. Era inaugurada, oficialmente, a agência espacial americana (NASA), e os soviéticos lançavam o satélite Sputnik 3.

Ainda naquele ano de 1958, o festival de jazz de Newport, nos EUA, reunia artistas do calibre de Ella Fitzgerald, Billie Holiday, Carmen McRae, Miles Davies, Thelonious Monk, Bill Evans e John Coltrane. No Brasil, as cantoras Maysa, Nora Ney, Eliseth Cardoso e Dalva de Oliveira faziam sucesso e lançavam seus discos. Boris Pasternak ganhava o Prêmio Nobel de Literatura e Aldous Huxley publicava Brave new world revisited. Nas ciências sociais, Claude Lévi-Strauss publicava sua Anthropologie structurale; Raymond Williams, Culture and society 1780-1950; C. Wright Mills, The causes of World War III; e Ralf Dahrendorf, seu Homo sociologicus.

Era uma época de confiança no progresso, no desenvolvimento, nas possibilidades técnicas e nas transformações políticas; de agitação e ousadia artística e cultural, de renovação política da esquerda após as revelações do XX Congresso do Partido Comunista da União Soviética. Após a Conferência de Bandung (em 1955), dava-se a ascensão do nacionalis놈 mo, decaía o colonialismo europeu e persistia సे a "guerra fria", mas seu sistema dicotômico já ¿ apresentava fissuras pela posição de não alinhamento e neutralidade de alguns países. No เุ๋ Brasil, após algumas tentativas golpistas, vi-

o ¿ econômico no período. A população beirava os

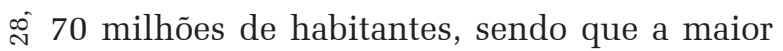

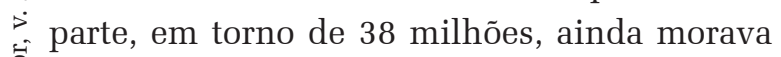
na zona rural (IBGE, 2008).

A sociologia no Brasil, então parcialmente institucionalizada e acadêmica, buscava consolidar-se em torno de temas e abordagens próprios, produzia seus primeiros balanços históricos e elaborações teóricas sistemáticas.
Dominavam a agenda questões como: desenvolvimento, industrialização, urbanização, mudança social, organização e integração ou aculturação, educação, populações rurais e indígenas, relações "raciais" etc., bem como a preocupação com teoria, ensino e pesquisa, processo de institucionalização e consolidação científica, problemas que eram considerados cruciais para a maturidade da própria sociologia no Brasil.

Guerreiro Ramos já possuía algumas obras de expressão - O processo da sociologia no Brasil (1953), Cartilha brasileira do aprendiz de sociólogo (1954), Introdução crítica à sociologia brasileira (1957) - e havia tido uma ruidosa participação no II Congresso Latino-Americano de Sociologia (realizado no Brasil em 1953), no qual apresentou algumas teses que suscitaram polêmica. Tentava, então, a elaboração de uma obra menos circunstancial, pois avaliava que havia passado a fase de desconstrução crítica da sociologia alienada e chegava o momento de fundar uma sociologia nacional. Com $A$ redução sociológica, Guerreiro Ramos pretendia coroar seus escritos críticos sobre a sociologia brasileira e seus esforços para fundamentar uma sociologia nacional e produzir uma teoria sociológica mais sistemática e intensiva. Na obra, o autor procura elaborar um instrumental teórico que fosse um método, uma atitude intelectual e existencial, um modo de assimilação crítica da produção estrangeira e uma ontologia.

Assim, primariamente, define a redução nos seguintes termos: "No domínio restrito da sociologia, a redução é uma atitude metódica que tem por fim descobrir os pressupostos referenciais, de natureza histórica, dos objetos e fatos da realidade social" (Ramos, 1996, p. 71). Ademais, a redução sociológica, segundo descrição do autor:

1) É atitude metódica [...] 2) Não admite a existência na realidade social de objetos sem pressupostos [...] 3) Postula a noção de mundo [...] 4) É perspectivista [...] 5) Seus suportes são coletivos e não individuais [...] 6) É um procedimento crítico-assimilativo da 
experiência estrangeira [...] 7) Embora seus suportes coletivos sejam vivências populares, a redução sociológica é atitude altamente elaborada (Ramos, 1996, p. 72-3, grifos do autor).

Além de tais características, a redução sociológica teria como "leis" (em sentido fraco, tendências): 1) a lei do comprometimento, estabelecendo que, nos países periféricos, a ideia e a prática da redução sociológica estariam ao alcance somente daqueles sociólogos que adotassem sistematicamente uma posição de engajamento ou de compromisso consciente com o seu contexto; 2) a lei das fases, segundo a qual os problemas colocados à ciência social não seriam casuais, pois obedeceriam à fase histórica - definida como totalidade dialética, porém só caracterizável a posteriori -, na qual a sociedade se encontraria, e na qual atuaria uma razão sociológica, isto é, "uma referência básica, a partir da qual tudo o que acontece em determinado momento de uma sociedade adquire o seu exato sentido" (p. 129); 3) a lei da universalidade dos enunciados gerais da ciência, que afirmava a generalidade de um elenco central de categorias aceitas por um círculo semântico de cientistas, com as quais se combinariam, entretanto, os imperativos do condicionamento nacional dos problemas e modos de equacionamento; e 4) a lei do caráter subsidiário da produção científica estrangeira, a partir da qual, em princípio, a produção estrangeira deveria ser submetida ao crivo das condições específicas, evitando-se a assunção dogmática, equivocada e disfuncional de ideias sem articulação com o contexto cultural (Ramos, 1996, p. 105-137).

$\mathrm{Na}$ fundamentação teórica da redução repousa a noção de que a realidade social - em sua complexidade - seria tecida por entes em sistemática conexão de sentido, não sendo fortuitos os fatos da vida social, mas "referidos uns aos outros por um vínculo de significação" (Ramos, 1996, p. 72). ${ }^{1}$ Inferia, daí, a categoria

1 Por vezes, Guerreiro Ramos refere-se aos fatos sociais como fenômenos sociais totais, demonstrando que estava sintonizado com a crítica à qual era submetida a concepção de fato social (como algo, coisa) e, por consequência, mundo, na qual os sujeitos, sua consciência e os objetos estariam intrinsecamente relacionados, existindo em profunda imbricação uns com os outros; o homem, como ser social, como ser-no-mundo (e ser-do-mundo), estaria fatalmente inserido num determinado contexto - suas ações, formas de consciência, seus valores e sua visão de mundo estariam ancorados na sua existência (espaçotemporal) histórica e socialmente particular.

Assim, o pensar (logo, também o pensamento científico e a sociologia em particular) só poderia ser algo relativizado, relacionado, dirigido a partir de uma perspectiva determinada. O sociólogo, como sujeito investigador, instrumentalizaria esse perspectivismo - de cunho social e não individual ${ }^{2}$ - na procura de um conhecimento autêntico, cuja funcionalidade estaria intimamente relacionada a uma intencionalidade dos sujeitos e referida à estrutura social e suas relações. Não haveria, portanto, posição neutra, equidistante ou superior; estariam os homens - e os sociólogos, no caso - condenados à ação. "Todo teorizar é extensão do fazer ao nível da representação”, Ramos (1996, p. 108) sentencia.

Ganhava, assim, alicerces teóricos mais sólidos a aspiração a uma "sociologia nacional”, antes demarcada pelo autor nos seguintes termos, em Introdução crítica à sociologia brasileira:

A sociologia, como toda ciência, é universal. É um método de pensar, corretamente, os fatos. Este método não é um na Alemanha, outro na Inglaterra, outro na França, outro no Brasil. É o mesmo em toda parte $[\ldots]$

Mas a universalidade da ciência, como técnica de pensar, não impede que a sociologia se diferencie nacionalmente. Esta diferenciação da sociologia é

o positivismo. Essa crítica, feita desde dentro por Marcel Mauss, sofria maior assédio de fora, mormente pela sociologia de influência fenomenológica, tendo em Georges Gurvitch e Jules Monerot alguns dos teóricos mais dedicados.

${ }^{2}$ Embora qualifique a perspectiva como algo social, o autor não explicita sua relação com os grupos (ou classes) sociais; aparentemente, tal relação é pensada mais em termos de nação - que, na construção do autor, não excluiria as relações de classe, mas que, em geral, enfatiza a existência social num espaço vital. 
incoercível. Desde que o sociólogo só existe nacionalmente, na medida em que o seu pensamento seja autêntico, terá de refletir as peculiaridades da circunstância em que vive. A sociologia se diferencia nacionalmente quanto aos temas e aos problemas de que trata. Desde que determinada sociedade se autodetermine, o trabalho sociológico tende aí a perder a disponibilidade e a tornar-se instrumento desta autodeterminação.

A sociologia, no Brasil, será autêntica na medida em que colaborar para a autoconsciência nacional, na medida em que ganhar em funcionalidade, intencionalidade e, consequentemente, em organicidade (Ramos, 1957c, 25-6).

Há, nessa construção, débito evidente para com a fenomenologia e a filosofia da existência: de Husserl, tomou a noção de redução fenomenológica ou epoquê, como atitude parentética - de pôr entre parênteses a existência efetiva do (ou no) mundo - e as de intencionalidade e perspectivismo da consciência; já de Heidegger absorve os conceitos de funcionalidade, ser-no-mundo e mundo. Obviamente, a dificuldade de utilização sociológica desses conceitos fez Guerreiro Ramos reconstruí-los na medida de suas necessidades, expurgando, por exemplo, a transcendentalidade do sujeito (eu) em Husserl - substituindo-a pela determinação social - e a dimensão existencial e ontologicamente dada que conceitos como serno-mundo e mundo adquiriam em Heidegger, s alterando-os no sentido de uma abordagem soک ciológica que privilegia as condições efetivas 安 de vivência e sociabilidade histórico-social, สี่ utilizando, para tanto, certas determinações do s⿱⺈ เి Há também, em certa medida, influência de $\therefore$ Dilthey (e sua filosofia da vida) nessa construn ção, especialmente nesse conceito. ${ }^{3}$

De posse desse arsenal teórico, urgiria à

¿ิ ${ }^{3}$ Já a comentada influência de Hegel, cuja herança - e de - "seus continuadores revolucionários" - ele próprio admi$\stackrel{\pi}{\geqslant}$ te (Ramos, 1957c, 213), parece ser um tanto remota, no ๘ sentido de que é mais um elemento geral de formação cul. tural que um autor constantemente presente em suas forTulações. Talvez certa concepção dialética da existência J - e possibilidades de autoconsciência - histórica esposada por Guerreiro Ramos seja devedora de Hegel. Quanto a Karl Jaspers, embora sua influência não pareça algo seminal, ainda não há um estudo detalhado das apropriações đ de Guerreiro Ramos. sociologia crítica atentar para a práxis, para os "imperativos práticos" do saber, pois a redução sociológica não seria uma atitude ingênua, desvinculada e desatenta de suas implicações, mas um expediente para a efetivação do saber autêntico, pois do conhecimento de uma determinada estrutura social derivariam responsabilidades e emanariam projetos. Conhecer seria, sobretudo, transformar, e a transformação da realidade social não seria apanágio do sociólogo.

A sociologia não é especialização, ofício profissional, senão na fase da evolução histórica em que nos encontramos, em que ainda perduram as barreiras sociais que vedam o acesso da maioria dos indivíduos ao saber. A vocação da sociologia é resgatar o homem ao homem, permitir-lhe ingresso num plano de existência autoconsciente. É, no mais autêntico sentido da palavra, tornar-se um saber de salvação (Ramos, 1996, 10-1, itálicos nossos). ${ }^{4}$

Mais tarde, ao retomar a questão por novo ângulo, conforme outro significado da redução - em Mito e verdade da revolução brasileira (1963) -, afirma que a sociologia teria como vício de origem o comprometimento com a ordem burguesa (daí, segundo ele, os sociólogos evitarem o tema da revolução). Entretanto, deveria, como "crítica da organização". ${ }^{5}$ ter como objetivo "submeter a existência

${ }^{4}$ O termo também foi usado por Hélio Jaguaribe (1979) num sentido cristão de saber revelado. Max Scheler (1986, p. 52), no entanto, parece ser a fonte do conceito, pois em 1925, já se referia "ao devir do mundo e ao devir intemporal do próprio princípio supremo ao seu modo de ser e existência, que atingem a 'determinação' do seu próprio devir somente no nosso saber humano ou em qualquer saber possível, ou pelo menos atingem algo sem o que não poderiam alcançar esta determinação. Chamemos esse saber, que tem por fim a divindade [...] 'saber de salvação ou de redenção' [...] que o nosso núcleo pessoal busca conquistar a participação no próprio ser e no princípio supremo das coisas, respectivamente onde esta participação lhe é concedida pelo próprio princípio supremo; ou então: é o saber onde o princípio supremo das coisas, enquanto se 'sabe' a si mesmo e ‘sabe' o mundo em nós e por nós, alcança ele próprio seu objetivo intemporal, como ensinavam primeiro Spinoza, depois Hegel e Eduard von Hartmann; ele consegue uma espécie de unificação consigo mesmo, a libertação de uma 'tensão' e de uma 'oposição originária' que nele residiam".

${ }^{5} \mathrm{O}$ conceito de organização tem dupla existência na obra do autor. De início, utiliza o conceito do mesmo modo que Alberto Torres (ver A organização nacional), com o significado de estruturação racional da sociedade; mais tarde, usa também o termo de modo aproximado ao da sociologia contemporânea - embora sem abolir uso da primeira forma -, acrescentando certo cunho libertário no sentido de 
social à reflexão, fundamentar-se na atitude parentética”, ${ }^{6}$ a saber, submeter à crítica incessante as condições sociais dadas e o próprio conhecimento que se quer hábil para fazê-lo. Assim, assumindo seu caráter de "saber de salvação", a sociologia possibilitaria também aos leigos um posicionamento crítico no mundo, capacitando-os à interpretação da realidade da existência, tornando-a "autêntica": "A 'promessa' da Sociologia é a de constituir-se num saber liberador, consistente em possibilitar ao cidadão comum, e não apenas aos especialistas, a qualidade mental que [Wright] Mills chama de ‘imaginação sociológica”’ (Ramos, 1963, p. 152).

Após buscar a autonomia da ciência na periferia em A redenção sociológica, Guerreiro Ramos buscou a superação da ciência social contemporânea em A nova ciência das organizações - livro esboçado desde 1973 e só publicado em 1981. Inicia a árdua tarefa fincando raízes na distinção entre racionalidade formal ou instrumental e racionalidade substantiva. A razão formal ou instrumental seria aquela baseada no "cálculo utilitário de consequências”, na relação exclusiva entre meios e fins; a substantiva resgataria a "razão como categoria ética” (Escola de Frankfurt), que independe de cálculos utilitários e expectativas de êxito (Weber), e revelaria percepções inteligentes das inter-relações de acontecimentos numa situação determinada (Mannheim), propiciando a existência da boa sociedade (Eric Voegelin). ${ }^{7}$

identificar a organização com o domínio férreo (por vezes burocrático) da vida social, mormente por meio das rotinas, sejam elas institucionais ou simplesmente cotidianas. Nesse último sentido, quando Guerreiro Ramos define o termo - embora não o faça sistematicamente -, limita-se a afirmar que a organização é "o segredo da servidão humana. É para os seres humanos o que a espécie é para os animais inferiores. Uniformiza as condutas, subordinando -as mecânica e dogmaticamente, reduz e até anula a liberdade"; sendo "pressuposto oculto da existência humana. É o veneno do cotidiano, cujos efeitos lesivos passam ordinariamente despercebidos. Somente quando se examina a existência humana do ponto de vista sistemático da organização, é que se pode perceber o quanto nela é patológico disfarçado em normalidade." (Ramos, 1963, 147 e 149 respectivamente).

${ }^{6}$ Em sua definição "A atitude parentética transcende a organização, é uma característica destreza da vida culta, de existência superior, ciosa de liberdade, que defende o ser humano contra o embrutecimento, a rotinização mental, a alienação" (Ramos, 1963, p. 149).

${ }^{7}$ As indicações das referências são fornecidas pelo próprio
Segundo GR, “[...] a racionalidade substantiva sustenta que o lugar adequado à razão é a psique humana [...] [que] deve ser considerada o ponto de referência para a ordenação da vida social, tanto quanto para a conceituação da ciência social em geral" (Ramos, 1989, p. 23). Na obra, pela primeira vez, censura Weber e Mannheim - por não terem levado adiante a distinção crítica entre as formas de racionalidade (ibidem, p. 4-7), e passa a buscar subsídios para a tarefa também em outros autores (Escola de Frankfurt, Eric Voegelin etc.). A partir da crítica da razão, investe contra a ciência social estabelecida, que se assentaria na racionalidade instrumental, característica do sistema de mercado, e teria estendido à cognição as formas de sociabilidade organizadas por ele. ${ }^{8}$

A ciência social moderna foi articulada com o propósito de liberar o mercado das peias que, através da história da humanidade e até o advento da revolução comercial e industrial, o mantiveram dentro de limites definidos [...] A moderna ciência social deveria, portanto, ser reconhecida pelo que é: um credo, e não verdadeira ciência (ibidem, p. 22).

Assim, A redução sociológica marca o fim da busca do autor por filiações, por resgate de uma tradição crítica do pensamento brasileiro, pela autonomia do pensar a partir da periferia do mundo e pela dignidade da teoria sociológica não importada dos grandes centros. Todavia, uma vez assentados os marcos de um pensamento autônomo e enraizado, segue-se à obra a busca pela crítica da ciência contemporânea e da hierarquização do saber, da funcionalidade e das relações promíscuas da ciência com a sociabilidade baseada no mercado, no capitalismo.

Ao seu tempo, A redenção sociológica cativou espíritos, suscitou controvérsias e, sobretudo, conferiu a alguns pensadores brasileiros (e estrangeiros) a ideia de que 'estávamos maduros para a teoria'. Ainda assim, a recepGuerreiro Ramos.

${ }^{8}$ Um exemplo disso, podemos acrescentar, seriam as teorias que propagam o interesse imediato (seja o homo economicus, seja o maximizador de benefícios etc.) como motivação humana essencial. 
ção da obra pelos contemporâneos do autor foi distinta e algo controvertida. Imediatamente saudaram-na Benedito Nunes (1958) e Teotônio (dos Santos) Júnior (1958). ${ }^{9}$

Benedito Nunes, em artigo publicado no mesmo ano, ${ }^{10}$ ressaltava os usos e redefinições da fenomenologia (e da redução), da razão histórica (a partir de então "sociológica”), do perspectivismo e dos conceitos de intencionalidade e de mundo (refuncionalizado para uma concepção referida ao contexto sócio-histórico) presentes em Husserl, Dilthey, Ortega y Gasset e Heidegger, respectivamente. O comentarista identificava, em A redução..., um método crítico e reflexivo, promissor não só no domínio da sociologia.

O livro do professor Guerreiro Ramos, A redução sociológica (introdução ao estudo da razão sociológica) constitui o primeiro ensaio de importância, que conseguiu aplicar à realidade brasileira, sob a instigação de sua problemática social, as intuições válidas que estão incorporadas hoje, definitivamente, à trajetória do pensamento filosófico contemporâneo. Além disso, parece-nos que esse livro aponta uma perspectiva alentadora para o desenvolvimento da filosofia no Brasil, que sempre ocupou entre nós uma posição indigente, de alienação acadêmica e de marginalismo cultural (Nunes, 1996, p. 200).

Embora estabeleça ligações entre as formulações de Guerreiro Ramos e dos autores $\stackrel{2}{2}$ citados, Benedito Nunes, indo ao encontro das afirmações do sociólogo brasileiro, não identificava, na obra, uma incursão do campo da fenomenologia, no sentido de proceder a uma nvestigação das formas de existência do social, uma fenomenologia do social.

Já, de modo contrário, Paulo Dourado de Gusmão (apud Ramos, 1996) ${ }^{11}$ via os esforços de Guerreiro como um empreendimento fenomenológico, superando as tentativas de Geor-

9 Também Mario Chamie e Haroldo de Campos, pioneiros da poesia práxis e do concretismo, manifestaram seu apreço e afinidade, no campo da estética literária, com as ideias presentes em A redução sociológica (Ramos, 1996, I p. 14).

10 “Consideração sobre a redução sociológica”. O texto aqui citado refere-se à reedição em Ramos (1996).

${ }^{11}$ Cf. Introdução à Sociologia (1959) e Teorias Sociológicas (1962), obras do autor. ges Gurvitch de promover um aprofundamento na realidade de modo a vencer formas epidérmicas e chegar à essencialidade do social.

Já em resenha efetuada por ocasião da publicação de A redução..., Teotônio Júnior (Theotônio dos Santos) comentava efusiva e febrilmente a obra. Assinalava que "a redução sociológica não pretende ser uma teoria sociológica, mas antes um método de trabalho que permite ao sociólogo brasileiro um instrumento de análise da teoria sociológica estrangeira" (p. 192-3); ainda assim, afirmava que se estava diante de uma nova ontologia (Teotônio Júnior, 1958, p. 195). Por fim, aproximava Guerreiro Ramos de um obtuso marxismo e sentenciava: A teoria da sociedade brasileira e a redução sociológica abrem-se-nos, assim, o caminho para uma teoria do mundo, do passado, do presente e do futuro, para uma nova concepção do espaço e do tempo, para, enfim, uma nova metafísica. Esta é a consequência lógica que Guerreiro Ramos não pôde tirar dado o caráter limitado do seu livro e sua obra à Sociologia. Consequência implícita, mas não afirmada (Teotônio Júnior, 1958, p. 194).

De fato, jamais afirmada. Apesar da inconsequência das palavras, temos aí uma ideia do impacto de A redução... em alguns jovens intelectuais brasileiros naquele momento. ${ }^{12}$

Por outro lado, a esquerda tradicional manifestava certa ambiguidade em relação ao autor e à obra. ${ }^{13}$ Jacob Gorender, então militante do PCB, em artigo publicado na revista Estu-

12 Também Rui Mauro Marini (2008), que foi professor assistente de Guerreiro Ramos no curso de Sociologia na Escola de Serviço Público do DASP (Departamento de Administração do Serviço Público) e com seu apoio foi encaminhado para prosseguir os estudos na França, assim define a influência exercida sobre ele: "Figura marcante era ali [na EBAP, Escola Brasileira de Administração de Empresas, no Rio de Janeiro] Alberto Guerreiro Ramos, professor de Sociologia, crítico irreverente de tudo que cheirasse a oficialismo, eclético incorrigível, aberto às novas ideias que se originavam de Bandung e da CEPAL; sua influência sobre mim, naqueles anos, foi absoluta." Ironicamente, o nacionalismo de Guerreiro Ramos nos anos 1950 seria poderosa influência sobre a extrema-esquerda internacionalista dos anos 1960-1970, contrastando vivamente sua distância com relação ao marxismo e suas concepções táticas do desenvolvimento com as teses de estagnação e dependência desses seus admiradores.

${ }^{13}$ Pouco tempo depois, em 1960-1961, visitou a China, a Iugoslávia e a União Soviética a convite do PCB; entretanto, de volta ao Brasil, manifestou-se criticamente nos jornais a respeito de tais países 'socialistas', o que lhe trouxe a malquerença de muito pecebistas. 
dos Sociais ("Correntes sociológicas no Brasil", $\mathrm{n}^{\mathrm{o}}$. 3-4, de set./dez. 1958), referia-se às análises do livro de Guerreiro Ramos afirmando que...

\begin{abstract}
Nós, comunistas, consideramos, e já o dissemos numa Declaração [de Março de 1958] que esta contradição [nação x antinação, identificada por Guerreiro Ramos] se tornou a principal, a dominante da sociedade brasileira, no atual período de sua vida. Trata-se de uma contradição que polariza a nação em desenvolvimento, com as suas forças progressistas e revolucionárias em expansão (dentro de marcos capitalistas, únicos possíveis no momento), em oposição ao imperialismo norte-americano e aos círculos econômicos e sociais, que o apoiam internamente [...] O Sr. Guerreiro Ramos chegou à essência do processo histórico [...] (Gorender, 1996, p. 207-8). ${ }^{14}$
\end{abstract}

Porém, para o crítico, Guerreiro Ramos não o teria feito "sem padecer de estreiteza específica". Gorender condenava-lhe o "ecletismo" e a recorrência às filosofias "burguesas" (como a fenomenologia, o existencialismo) e a autores como Husserl, Heidegger, Jaspers e Mannheim; reprovava ainda a concepção de uma "ideologia do desenvolvimento" (cujo formulador seria o ISEB), de uma "sociologia nacional" e o que entendia ser uma tentativa de submeter as massas à ideologia burguesa por meio da dissimulação das contradições de classe. E arrematava: "Limitamo-nos a assinalar este fenômeno bem brasileiro: ideólogos da burguesia de um país subdesenvolvido, a qual ainda tem um papel progressista a desempenhar, aceitam como padrão espiritual a filosofia decadente da burguesia imperialista" (Gorender, 1996, p. 216).

É frustrante que o grande adversário de Guerreiro Ramos, no terreno da teoria sociológica, não tenha se manifestado explicitamente a respeito de A redução sociológica. Florestan Fernandes, naquele mesmo ano de 1958, iniciava um balanço da atividade científica no

${ }^{14} \mathrm{O}$ texto de Gorender aqui citado consta da $2^{\mathrm{a}}$ edição (de 1965 e reeditada em 1996) de A redução sociológica, tendo sido incluído pelo próprio Guerreiro Ramos que o considerou "o mais eminente documento crítico que um militante do Partido Comunista já produziu no Brasil” (Ramos, 1996, p. 29).
Brasil em A etnologia e a sociologia no Brasil. O capítulo V dessa obra - já publicado no mesmo ano como artigo na Revista Brasileira de Estudos Políticos ${ }^{15}$ - intitula-se "O padrão de trabalho científico dos sociólogos brasileiros". Nele, o autor criticava alguns pontos da comunicação de Guerreiro Ramos no II Congresso Latino-Americano de Sociologia, de 1953, e iniciava uma polêmica que se desenrolaria por longo tempo (Bariani, 2003).

Naquele escrito, o sentido da crítica dirige-se ao caráter do trabalho científico e seus vínculos, Florestan censura a "falácia" que seria considerar impositivas as obrigações do sociólogo em relação ao sistema de interesses e de valores da nação e, de outro modo, negligenciar as obrigações relacionadas ao sistema de normas e de valores do saber científico (Fernandes, 1958, p. 224). Os sociólogos deveriam se pautar pelos padrões mais rigorosos de trabalho científico; para tanto, caberia uma estratégia que contemplasse: 1) a escolha de questões relevantes para a análise sociológica, quase sempre perturbada pelo impacto de influências extracientíficas; 2) a promoção da necessária adequação de noções e categorias abstratas, elaboradas pelos sociólogos por meio da observação e da interpretação de fenômenos similares em países que reproduzem, de forma mais completa, o mesmo tipo de ordem social (Fernandes, 1958, p. 226).

Se, em A sociologia numa era de revolução social (1976), originalmente publicada em 1962, Florestan Fernandes abre espaço para algumas inflexões externas aos padrões científicos na condição de sociólogo, também de cidadão, e não dilata a distância em relação às posições de Guerreiro Ramos, em Sociedade de classes e subdesenvolvimento, publicado em 1968, Florestan Fernandes volta à carga contra Guerreiro Ramos ${ }^{16}$ e afirma que o equí-

${ }^{15}$ Embora o livro seja de 1958, o prefácio - no qual o artigo já é mencionado - data de 1956, fica, assim, obscura assim a data exata do texto. Mais tarde, o autor voltaria a publicá -lo, desta feita em A sociologia no Brasil (1977).

${ }^{16}$ A propósito, em prefácio à $2^{\mathrm{a}}$ edição de A redução sociológica, em 1963, Guerreiro Ramos remeteu fortes críticas ao sociólogo paulista. 
voco central de suas considerações se localizaria na própria concepção de sociologia que, ao pleitear um vínculo estrito com dada sociedade e uma irredutível especificidade históricosocial, acreditaria "que a própria natureza dos problemas sociológicos, a serem investigados, exige recursos conceptuais metodológicos e teóricos específicos e exclusivos”, posição que converteria "o sociólogo em ideólogo e leva -o a ignorar ou a subestimar os requisitos da explicação científica e, até, o que torna o conhecimento científico verdadeiramente útil”. Assim, é "a própria Sociologia que é posta em questão, pois ela seria, no fundo, a fonte de falsos problemas e de explicações mistificadoras" (Fernandes, 1972, p. 16, grifos do autor).

Observa, ainda, o sociólogo paulista que, mesmo se considerando a sociologia um produto orgânico de uma cultura - como, de certo modo Hans Freyer (e Guerreiro Ramos) - seria possível extrapolar e construir métodos e técnicas de uso universal. Desse modo, Florestan salva uma herança que também lhe seria própria e cerra fogo em Guerreiro Ramos (Fernandes, 1972, p. 17). Ao abordar a questão de recursos teórico-metodológicos específicos (e exclusivos) e a questão da sociologia como algo universal, a despeito da organicidade da cultura, torna-se evidente o alvo das críticas: A redução sociológica.

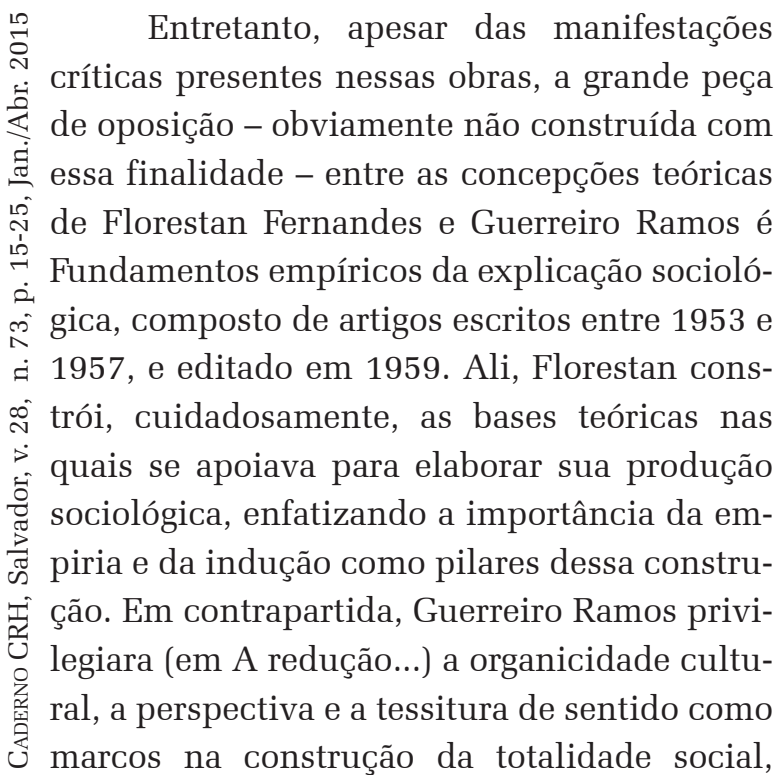

numa síntese dialética. As duas obras são, contemporaneamente, dois clássicos da sociologia brasileira, relativamente incomunicáveis, que ainda esperam um estudo comparativo.

De certa forma, ambas as obras, Fundamentos empíricos da explicação sociológica e A redenção sociológica, ilustram dois polos de diferentes concepções de sociologia, de ruptura ou continuidade com a tradição sociológica, de formas de abordagem da realidade brasileira e de modos de assimilação do conhecimento produzido nos grandes centros. Se, por um lado, Florestan Fernandes procura, nos fundamentos empíricos, por meio das teorias clássicas, a percepção de elementos para serem logicamente encadeados numa explicação da sociedade brasileira, joeirando os pequenos dados para formar um grande painel, por seu turno, Guerreiro Ramos, de certo modo, faz o caminho inverso: procura, na autenticidade de uma existência particular culturalmente detectável, uma totalidade a ser formatada com os instrumentos da sociologia clássica, mas sem o molde de uma teoria construída a partir de uma outra realidade social, isto é, tenta intuir uma totalidade primeira que será buscada nos elementos empíricos para recompor uma totalidade já pensada, refletiva, construída com base numa explicação particular de uma sociedade original.

Desse modo, para Florestan Fernandes, mormente nessa obra específica, a sociologia seria o modo universal de explicar ou compreender realidades particulares, por meio da indução de elementos empíricos, a partir da realidade supostamente mais desenvolvida, adiantada, consolidada, madura, da sociedade capitalista; para Guerreiro Ramos, principalmente em A redenção..., a sociologia seria uma forma de, através da percepção da originalidade da existência social específica, entender, por meio de uma teorização particular, como os elementos se combinam na construção de uma sociedade e de uma sociabilidade únicas, singulares. Aqui estão dadas as grandes tendências da interpretação sociológica no Brasil. 
Fora do Brasil, a recepção do trabalho de Guerreiro Ramos, e de A redução sociológica em particular, foi discreta. Embora já houvesse sido citado por Sorokin como um dos destacados sociólogos que faziam avançar a sociologia geral e sistemática (Sorokin, p. 636), a repercussão maior foi entre os estudiosos latino-americanos, mormente os radicados no México, onde $A$ redução... foi editada e comentada. Em 1959, a obra foi publicada no México e trazia consigo introdução de Oscar Uribe Villegas (1959), na qual ressalta o potencial de descolonização acadêmica contido nas propostas do sociólogo brasileiro. Também, em artigo posterior, na Revista Mexicana de Sociologia, Villegas (1959) utiliza-se dos critérios contidos na obra para classificar situações de desenvolvimento e subdesenvolvimento. Ainda nessa revista, Jorge Martinez Rios (1960) discute o uso da redução como instrumento crítico ao alcance dos intelectuais latino-americanos. Em geral, as recepções ocupam-se com o potencial crítico da obra em termos de problematização das instituições, produção acadêmica e esclarecimento dos intelectuais. ${ }^{17}$

Meio século depois, A redução sociológica ainda é um livro mais comentado que estudado, mais citado que propriamente lido e, curiosamente, mais exaltado que sistematicamente criticado. Imediatamente, é possível identificar ao menos dois aspectos da obra que ganharam contraste com o tempo: um mais datado e que pior sobreviveu ao peso dos anos; outro menos contextual, que ganha maior interesse e vigor com o tempo e os rumos que a sociologia tomou.

$\mathrm{O}$ aspecto do nacionalismo, do industrialismo e do progresso já acumulou bastante bolor, denunciando a senilidade de uma visão que defendia uma autonomia circunscrita e um rumo nacional-burguês para o desenvolvimento do capitalismo na periferia. Politicamente, foi solapado taticamente pelos inimigos em 1964 e, estrategicamente, pelo

17 Tais menções e fontes são devidas a Ariston Azevedo (2006), que as pesquisou cuidadosamente. desenlace das situações políticas colocadas às classes sociais por meio das circunstâncias do desenvolvimento do capitalismo mundial. Já intelectualmente, sucumbiu ao pragmatismo de seus próprios compromissos, perdendo fôlego na interpretação do mundo periférico contemporâneo, devido à tibieza teórica das suas posições. ${ }^{18}$

Já o aspecto de construção de uma sociologia intimamente ligada a uma ontologia de raízes filosóficas e uma metodologia crítico -reflexiva, enraizadas no pensamento clássico e distantes do empirismo e do comportamentalismo, permanece cada dia mais vivo. Ainda que o desenvolvimento da sociologia (mormente brasileira) tenha tomado rumo distinto desse, as possibilidades de um pensamento crítico que não desconsidere uma perspectiva particular no mundo e a condição mais duradoura da existência social, que não seja refém dos contextos mínimos, dos fatos e dados empiricamente coletados e organizados em termos de causalidades imediatas, da quantificação e da racionalidade mínima e interessada dos agentes, ainda são muito promissoras. Esse aspecto de ligação entre o perspectivismo do lugar no mundo e a filiação crítica à tradição do pensamento ocidental é, ainda, um desafio para a sociologia, atualíssimo na agenda, pouco aprofundado pelas soluções de diluição da sociologia num pretenso curso geral, nem das que apregoam a singularidade do pensamento periférico.

De todo modo, não obstante os problemas, com A redução sociológica, nunca fomos tão cosmopolitas em nossa situação localizada e, concomitantemente, nunca fomos tão locais em nosso cosmopolitismo.

Recebido para publicação em 15 de maio de 2014 Aceito em 11 de dezembro de 2014

${ }^{18}$ Desafortunadamente, parte das tentativas de crítica da colonização do saber se alimenta nessa fonte, comprometendo o vigor da análise. 


\section{REFERÊNCIAS}

AZEVEDO, Ariston. A sociologia antropocêntrica de Alberto Guerreiro Ramos. Tese (Doutorado em Sociologia Política) - Universidade Federal de Santa Catarina, Florianópolis, 2006.

BARIANI, Edison. A sociologia no Brasil: uma batalha, duas trajetórias (Florestan Fernandes e Guerreiro Ramos). Dissertação (Mestrado em Sociologia) - Universidade Estadual Paulista, Araraquara, 2003.

. Nacional por depuração. Perspectiva, São Paulo, UNESP, v. 28, p.105-118, 2006.

Guerreiro Ramos e a redenção sociológica: capitalismo e sociologia no Brasil. Tese (Doutorado em Sociologia) - UNESP, Araraquara, 2008.

FERNANDES, Florestan. A etnologia e a sociologia no Brasil: ensaios sobre aspectos da formação e do desenvolvimento das ciências sociais na sociedade brasileira. São Paulo: Anhambi, 1958.

. Fundamentos empíricos da explicação sociológica. $2^{\mathrm{a}}$ ed. São Paulo: Companhia Editora Nacional, 1967.

. Sociedade de classes e subdesenvolvimento. $2^{\mathrm{a}}$ ed.

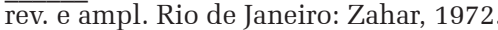

. A sociologia numa era de revolução social. $2^{\mathrm{a}}$ ed., reorg. e ampl. Rio de Janeiro: Zahar, 1976.

. A sociologia no Brasil: contribuição para o estudo de sua formação e desenvolvimento. Petrópolis: Vozes, 1977

GORENDER, Jacob. Correntes sociológicas no Brasil. In: RAMOS, Alberto Guerreiro. A redução sociológica. $3^{\mathrm{a}}$ ed. Rio de Janeiro: Editora da UFRJ, 1996. p. 203-25.

IBGE (Instituto Brasileiro de Geografia e Estatística). Dados históricos do censo, população residente. Disponível em http://www.ibge.gov.br/home/estatistica/populacao/ censohistorico/1940_1996.shtm. Acesso em 14 abr. de 2008.

JAGUARIBE, Hélio. A crise brasileira. In: SCHWARTZMAN, Simon (sel. e introd.). O pensamento nacionalista e os "Cadernos de Nosso Tempo". Brasília: UNB/Câmara dos Deputados, 1979, p. 131-70. (Biblioteca do pensamento político republicano).

MARINI, Ruy Mauro. Memória. Archivo de Ruy Mauro Marini. CEME Centro de Estudos Miguel Enriquez. เ2 Archivo Chile - Historia Politica Social, Movimiento จ Popular. Disponível em: http://www.archivochile.com/ Ideas_Autores/maurinirm/01sobre/marini_sobre00003. pdf. Acesso em 14 abr. 2008.
NUNES, Benedito. Consideração sobre a redução sociológica. In: RAMOS, Alberto Guerreiro. A redução sociológica. $3^{\text {a }}$ ed. Rio de Janeiro: Editora da UFRJ, 1996. p. $189-200$.

RAMOS, Alberto Guerreiro. Cartilha brasileira do aprendiz de sociólogo. Rio de Janeiro: Andes, 1954.

Introdução crítica à sociologia brasileira. Rio de Janeiro: Andes, 1957.

Mito e verdade da revolução brasileira. Rio de Janeiro: Zahar: 1963.

A nova ciência das organizações: uma reconceituação da riqueza das nações. 2.ed. Rio de Janeiro: Ed. FGV, 1989.

O processo da sociologia no Brasil: esquema de uma história das idéias. Rio de Janeiro: [s. n.], 1953.

A redução sociológica: introdução ao estudo da razão sociológica. Rio de Janeiro: ISEB, 1958.

Mito e verdade da revolução brasileira. Rio de Janeiro: Zahar Editores, 1963. UFRJ, 1996

A redução sociológica. $3^{\text {a }}$. ed. Rio de Janeiro: Ed.

SODRÉ, Nelson Werneck. A verdade sobre o ISEB. Rio de Janeiro: Avenir, 1978. (Depoimento, 4).

\section{Brasil, 1992}

A ofensiva reacionária. Rio de Janeiro: Bertrand

RÍOS, Jorge Martinez. La redución sociológica como tarea metódica-práctica de los sociólogos latinoamericanos. Revista Mexicana de Sociologia, México-DF, v. XXII, n. 2, p. 583-92, mai./ago. 1960.

SCHELER, Max. Visão filosófica do mundo. São Paulo: Perspectiva, 1986 (Debates, 191).

SOROKIN, Pitirim A. Câmbios en la sociologia durante los passados cincuenta años. Revista mexicana de sociología, v. 40, n. 6, jul./agosto 1956. p. 635-640.

TEOTÔNIO JÚNIOR (Teotônio dos Santos). Resenha do livro "A redução sociológica", de Guerreiro Ramos. Revista Brasiliense, São Paulo, n. 19, p. 189-195, set./out. 1958.

VILLEGAS, Oscar Uribe. Aportaciones del repertorio conceptual estadístico a la comprensión sociológica. Revista Mexicana de Sociologia, v. 21, n. 2, may-aug, 1959, pp. 649-662.

. Introducción. In: RAMOS, Alberto Guerreiro. La reducción sociológica: Introdución al estúdio da la razón sociológica. México-DF: Universidade Nacional Autônoma de México, 1959, p. 11-33. 
BIRTH CERTIFICATE: sociological reduction in its publishing context

\author{
Edison Bariani
}

More than half a century after the publication of Alberto Guerreiro Ramos's "The Sociological Reduction”, it is still a milestone in social sciences, especially for sociology in Brazil. However, some things still must be made clear on the social and intellectual context in which the work was produced, as well as its critical reception in that moment. There are also some aspects to be analyzed from the current perspective, that is, a review must be made of the importance of this work in Brazilian culture and what parts are out of touch and what parts remain relevant nowadays.

KEYwords: Guerreiro Ramos. Sociological Reduction. Periphery. Reception. Brazilian Sociology.
EXTRAIT DE NAISSANCE: la réduction sociologique dans le contexte de sa publication

\author{
Edison Bariani
}

Plus d'un demi siècle après la publication de "La réduction sociologique" de Alberto Guerreiro Ramos, ce livre est toujours une référence pour les sciences sociales et surtout pour la sociologie au Brésil. Cependant il est nécessaire de mieux expliquer le contexte social et intellectuel dans lequel l'oeuvre a été écrite ainsi que la critique dont elle a été l'objet à l'époque. Mais certains aspects doivent encore être analysés dans une perspective actuelle, en d'autres termes, il est nécessaire de faire un bilan et une révision de l'importance de cette oeuvre dans la culture brésilienne en tenant compte de l'action du temps et de ce qui reste actuel voire de ce qui n’a pas encore été dûment analysé.

Mots-CLÉs: Guerreiro Ramos. Réduction Sociologique. Périphérie. Réception. Sociologie Brésilienne.

Edison Bariani - Doutor em Sociologia. Professor da Faculdade Santa Rita (FASAR) de Novo HorizonteSP, da Facudade de Itápolis-SP (FACITA), do IMES (Catanduva). Tem experiência na área de Sociologia, com ênfase em sociologia no Brasil, pensamento social e intelectuais, atuando principalmente nos seguintes temas: Guerreiro Ramos, intelectuais, política, nacionalismo, ISEB, sociologia brasileira, teoria sociológica, história da sociologia. Publicações recentes: Horror à isonomia: as eleições no Brasil em 2014. Contextualizaciones Latinoamericanas, v. 12, p. 1-8, 2015; Por uma história do pensamento sociológico brasileiro. Insight Inteligência (Rio de Janeiro), v. 65, p. 104-113, 2014; Reformas pela cimalhas: Silvio Romero e a crítica da educação no Brasil. Múltiplas Faces da Região, v. 11, p. 103, 2014. 
